\title{
A Sensitive and Low-cost Analytical Method for the Electrochemical Determination of Quercetin, Based on 1-Ethylpyridinium Bromide/Carbon Paste Composite Electrode
}

\author{
Francis Merlin Melataguia Tchieno ${ }^{1}$, Ignas Kenfack Tonle ${ }^{1}$, Evangeline Njanja ${ }^{1}$, Emmanuel Ngameni ${ }^{2}$ \\ ${ }^{1}$ Electrochemistry and Chemistry of Materials, Department of Chemistry, University of Dschang, Dschang, \\ Cameroon \\ ${ }^{2}$ Laboratoire de Chimie Analytique, Faculté des Sciences, Université de Yaoundé I, B.P. 812 Yaoundé, Cameroon \\ Correspondence: Ignas Kenfack Tonle, Electrochemistry and Chemistry of Materials, Department of Chemistry, \\ University of Dschang, Dschang, Cameroon. E-mail: itonle@yahoo.com
}

Received: March 25, 2015

Accepted: April 19, $2015 \quad$ Online Published: July 6, 2015

doi:10.5539/ijc.v7n2p27

URL: http://dx.doi.org/10.5539/ijc.v7n2p27

\begin{abstract}
We report a simple, sensitive and low-cost electrochemical procedure for the quantification of quercetin (QCT), a flavonoid and an antioxidant, based on 1-ethylpyridinium bromide modified carbon paste electrode. A 1-ethylpyridinium bromide/carbon paste composite electrode was used. The cyclic voltammogram of QCT showed two oxidation peaks at $+0.575 \mathrm{~V}(v s \mathrm{Ag} / \mathrm{AgCl} / 3 \mathrm{M} \mathrm{KCl})$ and $+0.865 \mathrm{~V}(v s \mathrm{Ag} / \mathrm{AgCl} / 3 \mathrm{M} \mathrm{KCl})$, and a reduction peak at $+0.371 \mathrm{~V}(v s \mathrm{Ag} / \mathrm{AgCl} / 3 \mathrm{M} \mathrm{KCl})$ in $\mathrm{HCl} / \mathrm{KCl}$ solution at $\mathrm{pH} 1$. Differential pulse voltammetry (DPV) analysis in $\mathrm{HCl} / \mathrm{KCl}$ at $\mathrm{pH} 1$ showed three well-defined oxidation peaks while a single peak was recorded in phosphate buffer at $\mathrm{pH} 3$. The peak currents of QCT significantly increased at the 1-ethylpyridinium bromide modified electrode in comparison with those recorded at the bare carbon paste electrode. This allowed the use of adsorptive stripping voltammetry to develop a simple and sensitive electroanalytical method for the determination of QCT. Key experimental parameters such as $\mathrm{pH}$ of the supporting electrolyte, the preconcentration time, the electrolysis potential, electrode composition, QCT concentration and interferents were investigated. The current response was found to be directly proportional to the concentration of QCT in the range from $2.48 \times 10^{-7} \mathrm{M}$ to $7.43 \times 10^{-6} \mathrm{M}$, leading to a detection limit of $4.48 \times 10^{-8} \mathrm{M}$. The developed analytical method was successfully applied to the determination of QCT in human urine samples.
\end{abstract}

Keywords: quercetin, 1-ethylpyridinium ions, electrochemical sensor, differential pulse voltammetry, modified carbon paste electrodes

\section{Introduction}

Quercetin (QCT), Scheme 1, is a flavonoid present in several human diets (onions, tea, apples, red wine etc). As health benefits, QCT has been shown to be an efficient anti-inflammatory (Gonzalez-Segovia et al., 2008; Burns et al., 2000; Teresita et al., 2001), anti-bacterial (Havsteen, 1983; Rauha et al., 2000; Dall'Agnol et al., 2003), anti-gastric ulcer (Izzo et al., 1994), anti-cancer (Sharififar et al., 2009), and anti-diabetic (Vessal et al., 2003). Also, it has protective effect on DNA damage (Undeger et al., 2004) and on human platelet aggregation (Cook \& Samman, 1996; Ren et al., 2003). These features have induced a great interest in the development of analytical methods for the detection and/or quantification of QCT. Thus, high-performance liquid chromatography (Osman et al., 1998; Jones et al., 1998), ultraviolet spectrophotometry (Ranjbari et al., 2012; He et al., 2007; Pejic et al., 2004), capillary electrophoresis (Cao et al., 2001; Wang et al., 2003) and spectrofluorimetry (Xiao et al., 2013) have been used for the development of assays for QCT determination.

A simple, fast, economical and sensitive method for the determination of QCT and other flavonoids in crude drugs or plants is highly desirable. Since most flavonoids are electroactive at modest oxidation potentials, electrochemical methods are increasingly being utilised for their analysis thanks to inherent advantages such as time-saving, simple operation, cheapness and high sensitivity when compared to the analytical methods previously mentioned. To this effect, different electrode configurations have been designed and used, such as self-assembled platinum nanoparticles/poly(hydroxymethylated-3,4-ethylenedioxylthiophene) nanocomposite (Yola \& Atar, 2014), $\beta$-cyclodextrin/graphene nanocomposite (Xiao et al., 2007), gold 
nanoparticles/p-aminothiophenol functionalised multi-walled carbon nanotubes (Hollman et al., 1996), and multi-walled carbon nanotubes-paraffin oil paste (Zhou \& Sadik, 2008).

About the quantification of QCT, some recent and relevant reports include the exploitation of a graphite oxide and ionic liquid modified electrode (Jiuji et al., 2013), or the use of Ag nanoparticles/1-ethyl-3-methylimidazolium bis(trifluoromethylsulfonyl) imide based $\beta$-cyclodextrin/epichlorhydrin composite electrode (Franzoi et al., 2010). On the other hand, the exploitation of ionic liquids (ILs) for the extraction of phenolic compounds from herbal products (Liu et al., 2014) and medicinal plants (Xu et al., 2012; Bogel-Lukasik et al., 2010a; Zhu et al., 2011) has been demonstrated during the past few years. In fact, ILs can create various types of interactions with substrates and organic compounds, hydrogen bonds, van der Waals, dipole-dipole, dispersive and electrostatic forces being the most common of these interactions (Bogel-Lukasik et al., 2010a; Bogel-Lukasik et al., 2010b; Bogel-Lukasik et al., 2010c; Domanska \& Bogel-Lukasik, 2005). This probably explains the resort to ILs as electrode component in electroanalysis for the determination of phenolic compounds. Their presence within a composite electrode can greatly enhance the electrochemical activity of the electrode by increasing the rate of electron transfer and even by decreasing the overpotential of the analyte as observed by Makeli and co-workers (Maleki et al., 2007; Safavi et al., 2008). In spite of the high number of ILs-modified electrode in electrochemistry as reviewed in 2011 by Opallo \& Lesniewski, cheap electroanalytical tools based on direct inclusion of ILs within a carbon paste electrode (CPE) for the detection of QCT are scarce. Moreover, choosing the best IL for a given application using modified electrodes devoted to electroanalysis is usually problematic, since it is not easy to anticipate on the final properties of the composite electrode. In this work, we built a simple, sensitive and stable ionic liquid/carbon paste composite electrode for the electrochemical determination of QCT. 1-Ethylpyridinium bromide was chosen as electrode modifier since pyridinium ILs incorporated in modified electrodes have been proven to display good catalytic ability towards the detection of electroactive organic compounds (Maleki et al., 2006). Additionally, this pyridinium-based IL has not been used in the past for the analysis of QCT, and we were interested in evaluating the possible exploitation of such a soluble and water miscible RTIL as QCT sensing component within a CPE.<smiles>O=c1c(O)c(-c2ccc(O)c(O)c2)oc2cc(O)cc(O)c12</smiles>

Scheme 1. The molecular structure of quercetin

\section{Experimental}

\subsection{Reagents and Chemicals}

Quercetin dihydrate was purchased from Roth chemical company (Kansas, United States, www.rothchemical.com), a stock solution of $2.07 \mathrm{mM}$ prepared in $\mathrm{MeOH}$ and stored at $4{ }^{\circ} \mathrm{C}$ in a refrigerator. This stock solution was later diluted to the desired concentrations by mixing with supporting electrolyte. Buffer supporting electrolyte solutions were prepared from $\mathrm{KH}_{2} \mathrm{PO}_{4}$ (Prolabo, England, www.uk.vwr.com) and $\mathrm{K}_{2} \mathrm{HPO}_{4}$ (Fisher scientific international, Loughborough, England, www.fisher.co.uk) or $\mathrm{HCl}$ (Pronalys AR, Australia, www.thermofisher.com.au) and $\mathrm{KCl}$ (Fisher scientific international). The buffer solutions were used immediately after preparation. The $\mathrm{pH}$ of buffer solutions was adjusted with molar basic or acidic solutions respectively prepared from pellets of $\mathrm{NaOH}$ (Prolabo) and commercial $\mathrm{HCl}$ solution. Ascorbic acid (Aldrich, Lyon, France, www.sigmaaldrich.com/france), uric acid (BDH-Prolabo, England, www.uk.vwr.com), dopamine hydrochloride and D-(+)-glucose both from Sigma-Aldrich (Lyon, France, www.sigmaaldrich.com/france), L-aspartic acid (Fisher Scientific International), citric acid monohydrate (J.T. Baker, Center Valley, United States, www.avantormaterials.com), $\mathrm{K}_{4}\left[\mathrm{Fe}(\mathrm{CN})_{6}\right]$ and $\mathrm{K}_{3}\left[\mathrm{Fe}(\mathrm{CN})_{6}\right]$ (Prolabo) were all of analytical grade. Ascorbic acid, dopamine, L-aspartic acid, citric acid and D-(+)-glucose solutions were prepared in double distilled water while uric acid solutions were prepared in $\mathrm{NaOH}$ solutions, and used immediately afterwards. Human urine was collected from healthy laboratory staff and used immediately thereafter. 


\subsection{Apparatus}

A $\mu$-Autolab potentiostat (type III) running with GPES software, supplied by EcoChemie, Utrecht (Holland) was used for the electrochemical measurements. A standard single compartment three electrode cell was used with an $\mathrm{Ag} / \mathrm{AgCl} / 3 \mathrm{M} \mathrm{KCl}$ reference electrode (Metrohm, Ref 6.0726.100) and a stainless steel rod counter electrode. The working electrode was a 1-ethylpyridinium bromide/carbon paste composite electrode prepared as described below. Electrochemical Impedance Spectroscopy (EIS) measurements were performed on a PalmSens potenstiostat with the parameters: maximum frequency $10^{4} \mathrm{~Hz}$, minimum frequency $0.1 \mathrm{~Hz}$, direct current voltage $0.18 \mathrm{~V}$ and alternating current voltage $0.001 \mathrm{~V}$. All electrochemical experiments were carried out without degassing the supporting electrolyte solution.

\subsection{Preparation of the 1-Ethylpyridinium Bromide/Carbon Paste Composite Electrode}

The bare CPE was prepared by thoroughly mixing graphite powder from Alfa (70\%) with silicone oil (30\%) serving as binder, until a homogenous paste was obtained. When 1-ethylpyridinium bromide (Alfa Aesar) was added as third component, its proportion was reported in percentage by weight in the whole composite electrode. The homogeneous paste was then firmly packed into the cavity $(2.5 \mathrm{~mm}$ inner diameter) of a Teflon tube, through which moves a screwed stainless steel rod which serves as electric contact.

\subsection{Electroanalytical Procedure}

Cyclic voltammograms (CV) were recorded using 1-ethylpyridinium bromide/carbon paste composite electrode (CPE-EPB) either in a phosphate buffer $(\mathrm{PB})$ or $\mathrm{HCl} / \mathrm{KCl}$ buffer solution containing QCT at a given concentration. This was followed by a cyclic potential sweep from $0 \mathrm{~V}$ to $+1.2 \mathrm{~V}$ at a $75 \mathrm{mV} \mathrm{s}^{-1}$ scan rate. Stripping analysis was carried out following a 2 step procedure: (i) a preconcentration step at open-circuit, during which the working electrode was immersed for a defined period of time in an aqueous solution of QCT under mild mechanical stirring and (ii) a detection step where the electrode was rapidly removed from the preconcentration solution, rapidly rinsed with double distilled water and transferred to the buffer detection solution in the electrochemical cell. The electrode response was then recorded using differential pulse voltammetry (DPV) with the following conditions: pulse amplitude $50 \mathrm{mV}$, step potential $5 \mathrm{mV}$, initial potential $0 \mathrm{~V}$ or $-0.2 \mathrm{~V}$, final potential $+0.7 \mathrm{~V}$ or $+1.0 \mathrm{~V}$ and equilibrium time $5 \mathrm{~s}$. Electrolysis potential, preconcentration time, $\mathrm{pH}$ of detection medium and composition of the modified carbon paste were optimised. Prior to each measurement, the electrode surface was renewed by polishing with a soft and smooth piece of paper. For chronocoulometric measurements, the potential was stepped from $0.0 \mathrm{~V}$ to $+0.9 \mathrm{~V}$ for a period of $250 \mathrm{~ms}$ with a sample time of $0.01 \mathrm{~s}$.

\section{Results and Discussion}

\subsection{Electrochemical Impedance Spectroscopic Characterisation}

EIS was used to characterise the bare and modified CPEs. Figure 1 shows the resulting Nyquist plots. In the high frequency region of Figure 1, a large and well-defined semicircle is observed. This indicates a high electron transfer resistance $\left(\mathrm{R}_{\mathrm{ct}}=1728.90 \Omega, \mathrm{C}_{\mathrm{dl}}=0.163 \mu \mathrm{F}, \mathrm{n}=0.88\right.$ ). Upon modification of CPE with EPB (Figure 1 inset), the size of the semicircle is greatly reduced $\left(\mathrm{R}_{\mathrm{ct}}=884.78 \Omega, \mathrm{C}_{\mathrm{dl}}=1.011 \mu \mathrm{F}, \mathrm{n}=0.37\right)$, indicating a very small interfacial electron transfer resistance and electrocatalytic capability of the modifier used. The positively charged EPB molecules attract the negatively charged $\left[\mathrm{Fe}(\mathrm{CN})_{6}\right]^{3-14-}$ and improved the electron transfer rate. The reduced electron transfer resistance at CPE-EPB $(10 \%)$ is a proof of the successful immobilisation of EPB in the CPE.

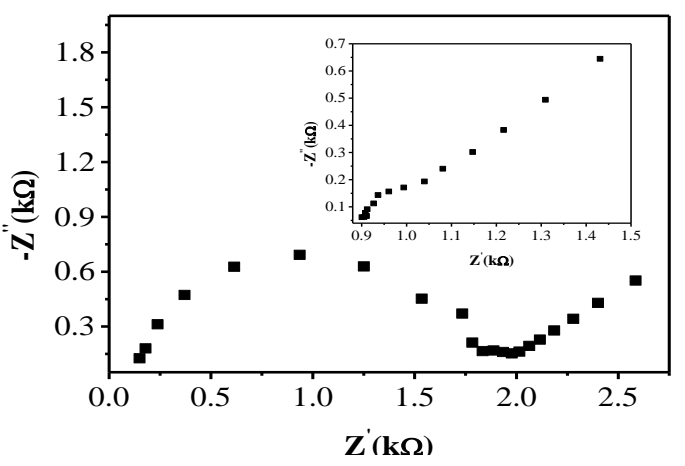

Figure 1. Nyquist plot of the EIS data of bare $\mathrm{CPE}$ in $0.1 \mathrm{mM}\left[\mathrm{Fe}(\mathrm{CN})_{6}\right]^{3-14-}$ containing $0.2 \mathrm{M} \mathrm{KCl}$. Frequency range from 0.1 to $10^{4} \mathrm{~Hz}$ and at the formal potential of $0.18 \mathrm{~V}$. Inset shows the EIS data of CPE-EPB (10\%) 


\subsection{Initial Electroanalytical Investigations}

Initial measurements were undertaken on $\mathrm{QCT}$ in $\mathrm{HCl} / \mathrm{KCl}$ buffer solutions at $\mathrm{pH} 1$. Figure 2a shows the cyclic voltammograms recorded using a bare CPE. The oxidation of QCT showed two peaks at $+0.575 \mathrm{~V}$ (peak 1) and $+0.865 \mathrm{~V}$ (peak 2), and a reduction peak appeared at $+0.371 \mathrm{~V}$ (peak 3) upon scan inversing. This behaviour, previously observed by Brett and Ghica (2003) is typical of organic compounds with the same structure as QCT. Peaks 1 and 3 correspond to the two-electron two-proton quasi-reversible oxidation-reduction of the hydroxyl groups on ring $\mathrm{B}$, merged with the irreversible oxidation of the hydroxyl group on $\mathrm{C} 3$ of ring $\mathrm{C}$ while peak 2 is a result of the oxidation of the hydroxyl group on C5. With DPV, three peaks were obtained (Figure 2b) both with bare CPE and with CPE-EPB (10\%).
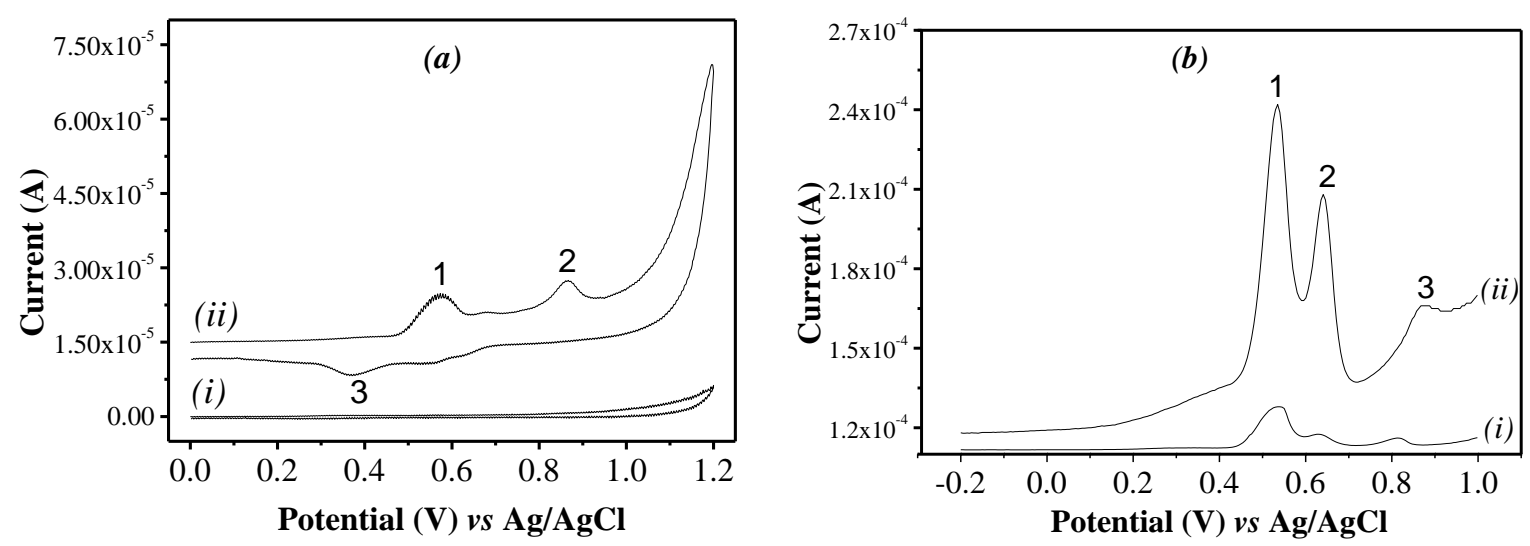

Figure 2. (a) Cyclic voltammetric response in $\mathrm{HCl} / \mathrm{KCl}(\mathrm{pH}$ 1) on bare $\mathrm{CPE}$ : (i) in blank electrolyte and (ii) in the latter containing $40.6 \mu \mathrm{M}$ QCT. Potential scan rate: $75 \mathrm{mV} \mathrm{s}^{-1}$. (b) DPV of $40.6 \mu \mathrm{M}$ QCT in $\mathrm{HCl} / \mathrm{KCl}$ (pH 1) on

(i) bare CPE and (ii) CPE-EPB (10\%)

Peak 2 on Figure $2 \mathrm{~b}$ can be attributed to the oxidation of the hydroxyl group on $\mathrm{C} 3$ of ring $\mathrm{C}$ while peaks 1 and 3 are due to the oxidation of the hydroxyl groups on ring B and C5 respectively (Brett \& Ghica, 2003). On the bare CPE, the DPV peak intensities were $9.77 \mu \mathrm{A}, 1.61 \mu \mathrm{A}$ and $2.07 \mu \mathrm{A}$ respectively for peak 1 , peak 2 and peak 3 (Figure 2b(i)). On CPE-EPB (10\%), the peak intensities were $85.5 \mu \mathrm{A}, 52.5 \mu \mathrm{A}$ and $11.8 \mu \mathrm{A}$ respectively (Figure $2 \mathrm{~b}(\mathrm{ii}))$. This enhancement of peak intensities could be reasonably explained by electrostatic interactions between the 1-ethylpyridinium moieties and QCT, such as cation- $\pi$ interactions between the positively charged EPB and the $\pi$ electron system of QCT. This result is useful and shows that the presence of EPB within the CPE has greatly enhanced the sensitivity of the electrode towards the detection of QCT. Otherwise, the conducting property of EPB has promoted the electron transfer rate between QCT and the bulk CPE. In addition, the electrode survives quite well despite the soluble character of the used IL which may have led to its leaching into the aqueous electrolyte solution. Strong cation- $\pi$ and $\pi-\pi$ interactions between the 1-ethylpyridinium moieties and the aromatic rings in graphite account for this electrode stability.

Increase in scan rate led to a positive shift of QCT peak potential, with a linear relationship obtained in the range $50-500 \mathrm{mV} \mathrm{s}^{-1}$ (Figure 3).

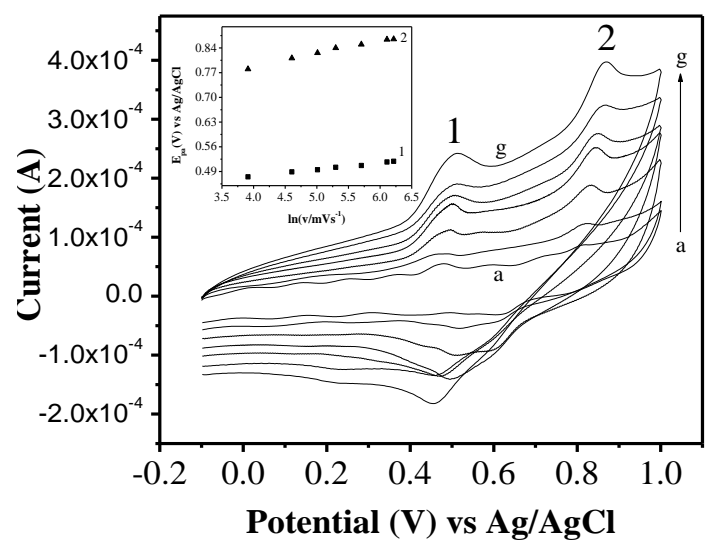

Figure 3. Cyclic voltammograms of $100 \mu \mathrm{M}$ QCT at CPE-EPB (10\%) in PB pH 3 at different scan rates (a-g: 50, $100,150,200,300,450$ and $500 \mathrm{mV} \mathrm{s}^{-1}$ ). Inset shows the plots of $E_{p}$ against $v^{1 / 2}$ 
According to Laviron, for an irreversible and adsorption-controlled electrode process, shift of anodic peak potential with scan rate is given by equation 1 (Laviron, 1974).

$$
\mathrm{E}_{\mathrm{pa}}=\mathrm{E}^{0}+\left(\frac{\mathrm{RT}}{(1-\alpha)_{\mathrm{n}_{\mathrm{a}} \mathrm{F}}}\right) \ln \frac{\mathrm{RT}_{\mathrm{k}_{\mathrm{s}}}}{(1-\alpha)_{\mathrm{n}_{\mathrm{a}} \mathrm{F}}}+\left(\frac{\mathrm{RT}}{(1-\alpha)_{\mathrm{n}_{\mathrm{a}} \mathrm{F}}}\right) \ln v
$$

where $\alpha$ is the charge transfer coefficient, $k_{s}$ is the standard rate constant and $n_{a}$ is the number of electrons involved in the charge transfer step. Other symbols keep their usual meanings. The corresponding linear regression equations are $\mathrm{E}_{\mathrm{pa} 1}=0.02 \ln \mathrm{v}+0.40(\mathrm{R}=0.998)$ and $\mathrm{E}_{\mathrm{pa} 2}=0.04 \ln \mathrm{v}+0.64(\mathrm{R}=0.995)$ (Figure 3 inset). From their slopes, (1- $\alpha) \mathrm{n}_{\mathrm{a}}$ values were calculated and found to be 1.28 and 0.64 respectively. Assuming $\alpha$ $=0.5$, then $\mathrm{n}_{\mathrm{a}}=2.6 \approx 3$ and $1.3 \approx 1$ respectively. This shows that peak 1 in Figure 3 is a merger of peaks 1 and 2 shown in Figure 2b(ii). In Figure 2b(ii), peak 1 could therefore be the result of the two-electron two-proton oxidation of the hydroxyl groups on ring B, peak 2 a one-electron one-proton oxidation of the hydroxyl group at $\mathrm{C} 3$ of ring $\mathrm{C}$ and peak 3 a one-electron one-proton oxidation of hydroxyl group on C5 of ring A (Scheme 2).

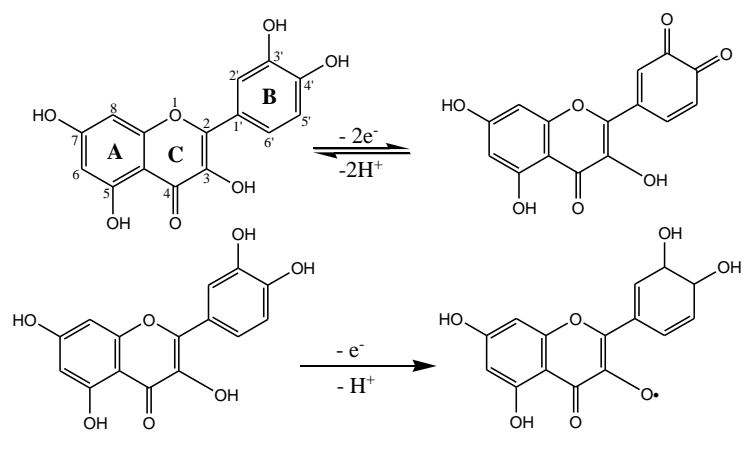<smiles>CC#CCCCC</smiles>

Scheme 2. The possible oxidation mechanism of QCT at CPE-EPB (10\%) sensor

\subsection{Optimisation of Experimental Conditions for Analytical Application}

\subsubsection{Optimisation of the Modified Carbon Paste Electrode Composition}

Since a comparison of the curves in Figure $2 b$ showed that the activity of the electrode is increased with the inclusion of EPB within the paste, the first parameter analysed herein was the proportion of the IL modifier in the electrode. The evolution of peak currents of QCT with mass of EPB in the carbon paste is shown in Figure 4, which shows that the signals of the working electrode depend on the amount of EPB in the paste.

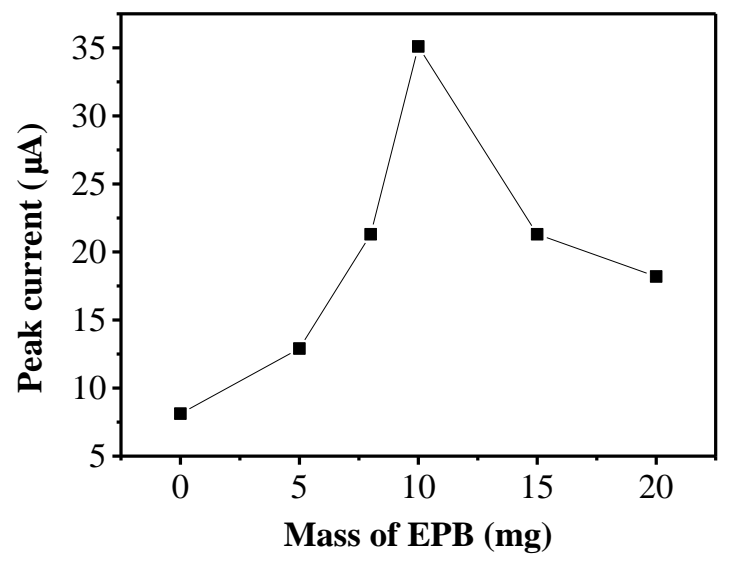

Figure 4. Variation of peak currents of $20.7 \mu \mathrm{M}$ QCT with mass of EPB in $100 \mathrm{mg}$ paste. The DPV curves were recorded in $0.1 \mathrm{M} \mathrm{PB}(\mathrm{pH} 3)$

The DPV peak currents of QCT initially increased as the percentage of EPB increased from 0 to $10 \%$, then 
decreased at higher EPB amounts. Therefore, a CPE containing $10 \%$ by mass in EPB was subsequently taken as the optimum electrode composition and the electrode as such obtained is herein designated CPE-EPB (10\%).

\subsubsection{Effect of $\mathrm{pH}$}

QCT bears hydroxyl and catechol-like functional groups in its structure (Scheme 1), and it is expected that the acidity of the supporting electrolyte affects its redox behaviour. Figure 5a presents the evolution of the anodic stripping voltammograms of QCT when the $\mathrm{pH}$ of buffer solutions used as detection media was varied from 1 to 9. The oxidation peak potential $\left(\mathrm{E}_{\mathrm{p}}\right)$ of QCT shifted negatively with increase in $\mathrm{pH}$.
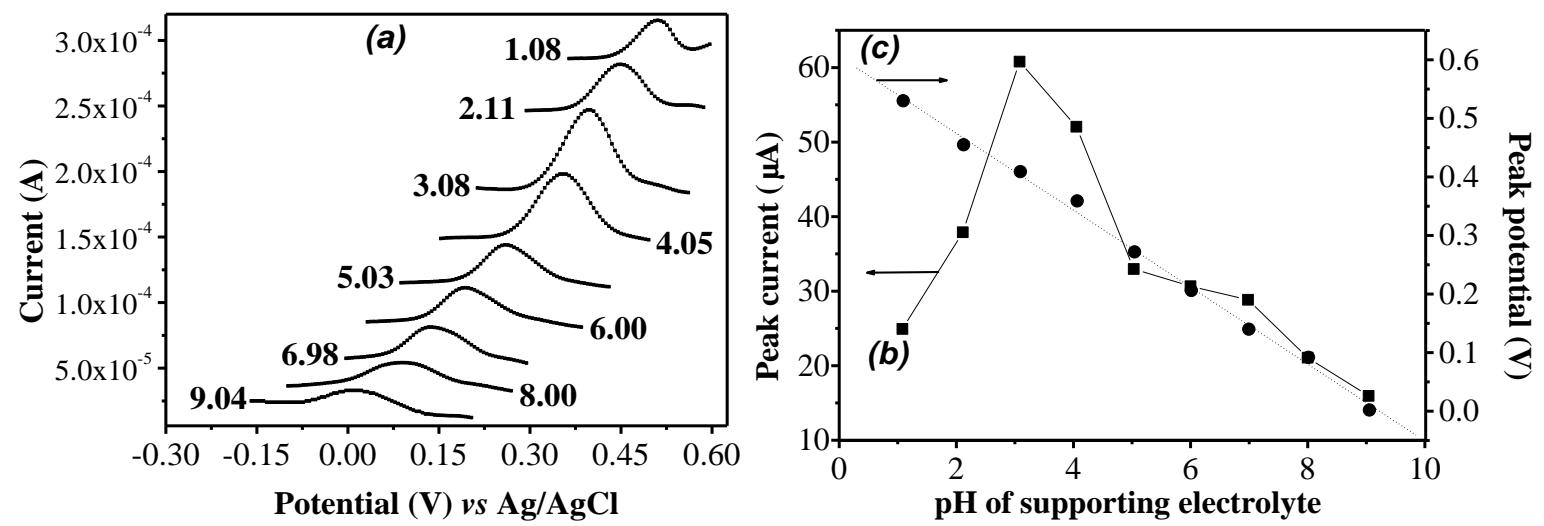

Figure 5. (a) Effect of detection medium $\mathrm{pH}(1.08,2.11,3.08,4.05,5.03,6.00,6.98,8.00$ and 9.04) on the anodic peak position of QCT, at CPE-EPB (10\%) in $20.7 \mu \mathrm{M}$ QCT. (b) Variation of the peak current as a function of pH of the detection medium. (c) Peak potential as a function of the $\mathrm{pH}$ of the detection medium

This behaviour corresponds to a typical $\mathrm{pH}$ dependence of the oxidation of polyphenolic compounds (Brett and Ghica, 2003). In Figure 5b, an increase in peak intensity with $\mathrm{pH}$ is noted, reaching a maximum at $\mathrm{pH} 3$ and followed by a subsequent drop of peak intensities beyond this value. A buffer with $\mathrm{pH} 3$ was taken as the best medium for the detection of QCT. Noticeable, at $\mathrm{pH}$ values above 9, a greenish-yellow coloration was observed in the electrochemical cell, which was attributed to the presence of the quinonic derivative of QCT resulting from its oxidation by dissolved oxygen (Tcheumi et al., 2010). Figure $5 c$ shows a linear relationship between $E_{p}$ and $\mathrm{pH}$, with a variation of $65 \mathrm{mV}$ per $\mathrm{pH}$ unit $(\mathrm{R}=0.998)$. This is typical of an oxidation involving an equal number of electrons and protons (Tcheumi et al., 2010; Tchieno et al., 2014).

\subsubsection{Effect of Preconcentration Time and Electrolysis Potential}

The oxidation peak current of QCT was low for preconcentration times less than $60 \mathrm{~s}$. Then, the electrode response increased significantly between 60 and $120 \mathrm{~s}$ where a plateau was reached (Figure 6a). Thus, an adsorptive equilibrium was probably reached after $130 \mathrm{~s}$ preconcentration. For subsequent analyses, the accumulation of QCT was performed for at least $3 \mathrm{~min}$ prior to its detection by DPV. Figure $6 \mathrm{~b}$ shows the variation of peak current as a function of electrolysis potential. A maximum is reached at $-0.3 \mathrm{~V}$ and the peak current drops beyond this value which was taken as the best compromise for the electrolysis of QCT at CPE-EPB (10\%).
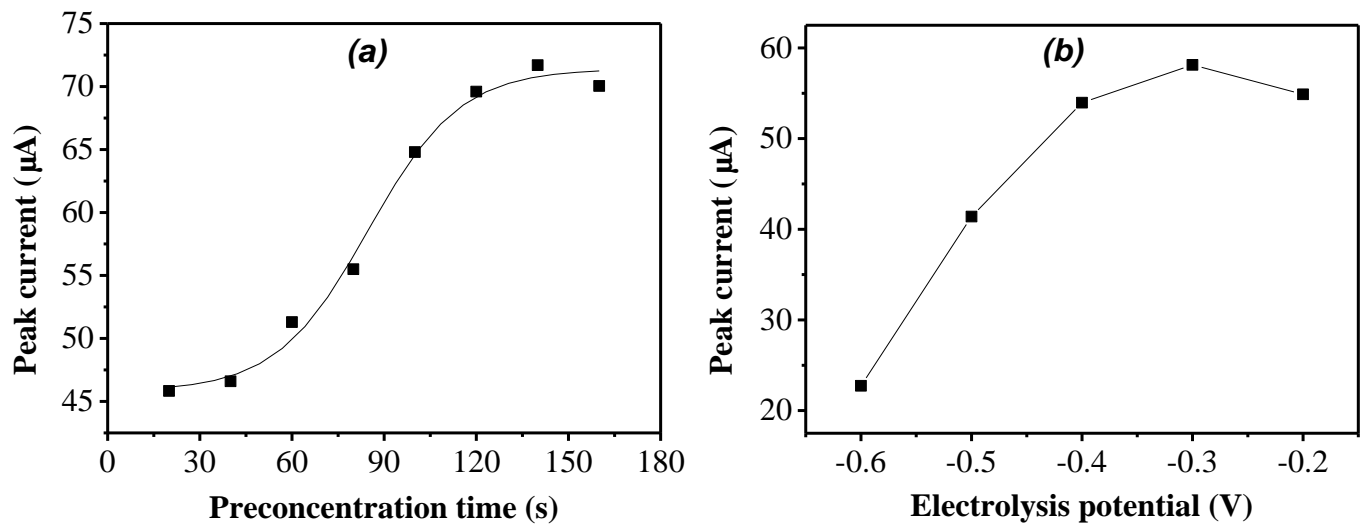

Figure 6. Dependence of current response at CPE-EPB (10\%) in $0.1 \mathrm{M} \mathrm{PB} \mathrm{(pH} \mathrm{3)} \mathrm{on} \mathrm{(a)} \mathrm{preconcentration} \mathrm{time} \mathrm{in}$ $0.248 \mu \mathrm{M}$ QCT and (b) electrolysis potential in $20.7 \mu \mathrm{M}$ QCT 


\subsection{Variation of QCT Concentration and Calibration Graph}

Under the optimised conditions established in previous sections, the concentration of QCT was varied in the range from $2.48 \times 10^{-7} \mathrm{M}$ to $7.43 \times 10^{-6} \mathrm{M}$ and Figure 7 depicts the DPV curves. The peak current $\left(\mathrm{I}_{\mathrm{p}}\right)$ increased with the concentration of QCT $\left(\mathrm{C}_{\mathrm{QCT}}\right)$, with a linear dependence following the equation $\mathrm{I}_{\mathrm{p}}(\mu \mathrm{A})=16.489$ $\mathrm{C}_{\mathrm{QCT}}(\mu \mathrm{M})-0.095$ (inset in Figure 7). A correlation coefficient of 0.999 was obtained for this calibration graph, thus indicating a good linearity between peak current and QCT concentration. The limit of detection defined as $3 \mathrm{~s} / \mathrm{m}$ (where $\mathrm{s}$ is the blank standard deviation $(\mathrm{N}=8)$ and $\mathrm{m}$ the slope of the calibration curve) was calculated and found to be $4.48 \times 10^{-8} \mathrm{M}$ QCT. Compared with other electrode configurations used for the determination of QCT, the studied composite electrode herein obtained by a simple and cost effective method gives rise to a limit of detection of the same order of magnitude (Lin et al., 2006; Piovesan \& Spinelli, 2014), or even better than those achieved with other sensors (He et al., 2007; Zheng et al., 2014).

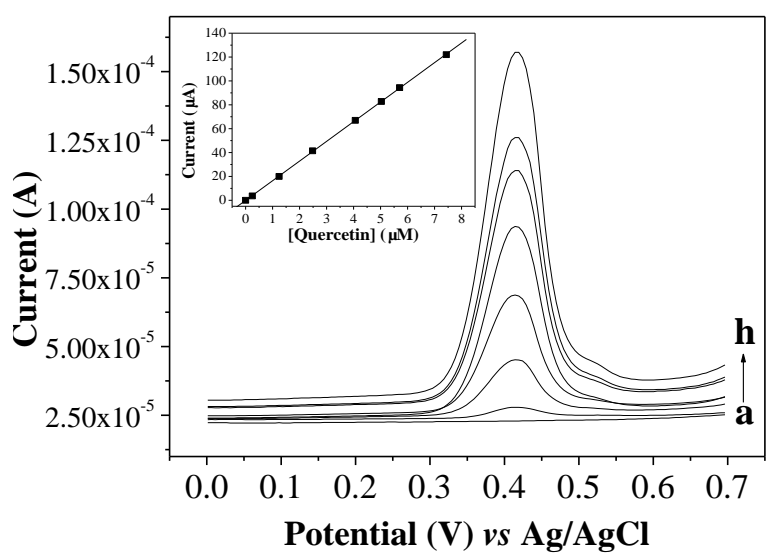

Figure 7. DPV curves obtained under optimised conditions in $0.1 \mathrm{M} \mathrm{PB} \mathrm{pH} 3$ at CPE-EPB (10\%) for various concentrations of QCT (a-h): 0, 0.248, 1.241, 2.481, 4.064, 5.030, 5.705 and $7.434 \mu \mathrm{M}$ QCT. The inset shows the corresponding calibration graph

\subsection{Chronocoulometric Studies}

Chronocoulometry is a powerful tool in identifying adsorption phenomena, in obtaining information on the kinetics of coupled homogeneous reactions and for the determination of the capacitive charge contribution (Inzelt, 2010) at the surface of an electrode. The total charge (Q) in the presence of adsorbed species can be written as in equation 2, called the Anson equation.

$$
\mathrm{Q}=\frac{2 \mathrm{nFAD} \mathrm{D}^{1 / 2} \mathrm{Ct}^{1 / 2}}{\pi^{1 / 2}}+\mathrm{Q}_{\mathrm{c}}+\mathrm{Q}_{\mathrm{ads}}
$$

where $\mathrm{n}$ is the number of electrons transferred, $\mathrm{F}$ is the Faraday constant, $\mathrm{A}$ is the surface area of the electrode, D is the diffusion coefficient, $C$ is the bulk concentration of the species, $t$ is the potential pulse width, $Q_{c}$ is the capacitive or double layer charge and $\mathrm{Q}_{\mathrm{ads}}$ is the faradaic component due to the oxidation of adsorbed species (Qu et al., 2010).

\subsubsection{Electrochemical Effective Surface Area}

From experiments performed in $0.2 \mathrm{mM}\left[\mathrm{Fe}(\mathrm{CN})_{6}\right]^{3-}$ solution containing $2 \mathrm{mM} \mathrm{KCl}$, the electrochemical effective surface areas (A) of bare CPE and CPE-EPB (10\%) were obtained. The diffusion coefficient of $\left[\mathrm{Fe}(\mathrm{CN})_{6}\right]^{3-}$ is $7.6 \times 10^{-6} \mathrm{~cm}^{2} / \mathrm{s}$ (Yin et al., 2010) and its $\mathrm{n}=1$. The $\mathrm{Q}-\mathrm{t}^{1 / 2}$ plots (not shown) for these experiments had slopes $11.91 \mu \mathrm{C} / \mathrm{s}^{1 / 2}$ and $237.80 \mu \mathrm{C} / \mathrm{s}^{1 / 2}$ in the case of bare CPE and CPE-EPB (10\%) respectively. The A-values found were $0.1984 \mathrm{~cm}^{2}$ and $3.9620 \mathrm{~cm}^{2}$ for bare CPE and CPE-EPB $(10 \%)$ respectively. This increase in electrochemical effective electrode surface area upon modification of CPE with EPB also accounts for the enhancement of the oxidation peak current of QCT noted in earlier sections. It is also further proof of successful immobilisation of EPB in the CPE.

\subsubsection{Diffusion Coefficient}

In the presence of pure supporting electrolyte alone, the total charge variation at CPE-EPB (10\%) was described by curve (i) (Figure $8(\mathrm{a})$ ) while curve (ii) of the same figure describes the variation of total charge at the 
electrode surface in the presence of QCT. Figure 8(b) shows the corresponding Q- $\mathrm{t}^{1 / 2}$ plots. Their slopes are $0.5632 \mathrm{mC} / \mathrm{s}^{1 / 2}$ and $0.5797 \mathrm{mC} / \mathrm{s}^{1 / 2}$ for Figure $8 \mathrm{~b}\left(i^{\prime}\right)$ and Figure $8 \mathrm{~b}\left(i^{\prime} i^{\prime}\right)$ respectively. From the slope of Figure $8 \mathrm{~b}\left(i^{\prime} i^{\prime}\right)$ and equation 2, a diffusion coefficient (D) of $4.52 \times 10^{-5} \mathrm{~cm}^{2} / \mathrm{s}$ was calculated for QCT, taking $\mathrm{n}=2$.
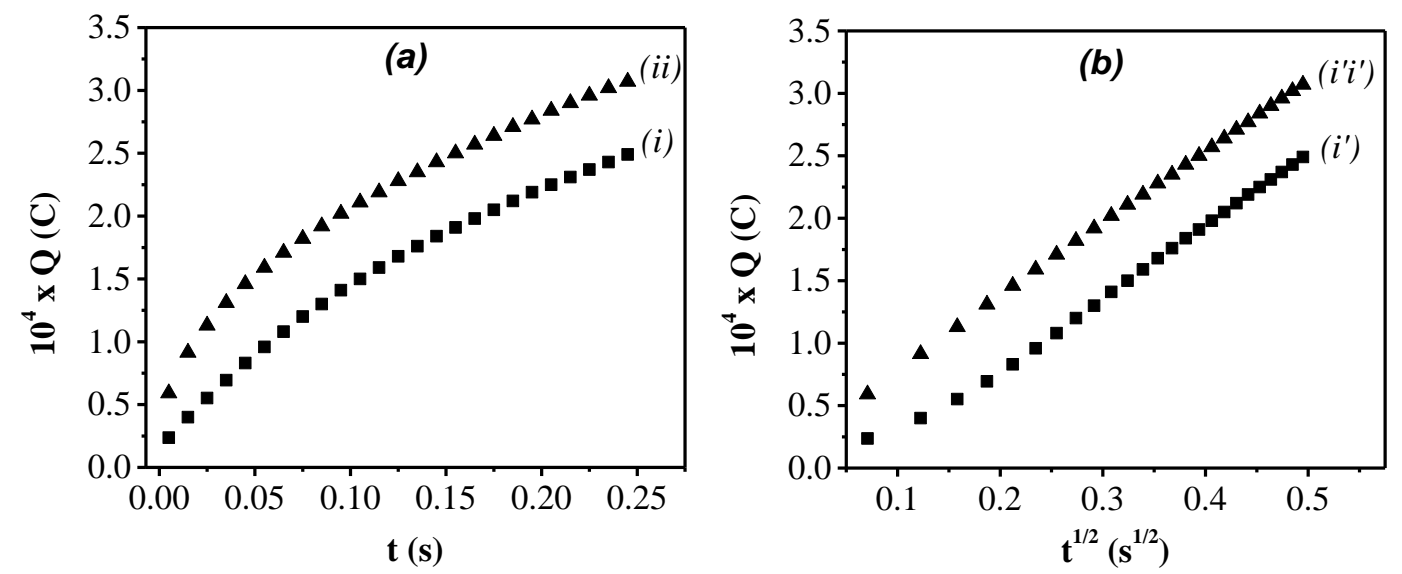

Figure 8. (a) Chronocoulograms recorded at CPE-EPB (10\%) in (i) pure supporting electrolyte alone and (ii) the presence of $100 \mu \mathrm{M}$ QCT. (b) Linear chronocoulometric plots from the data of the plots in (a) with: (i') pure supporting electrolyte and $\left(i^{\prime} i^{\prime}\right)$ in the presence of $100 \mu \mathrm{M}$ QCT

\subsubsection{Molecular Surface Coverage}

The intercept of Figure $8 b\left(i^{\prime}\right)$ gives $Q_{c}$, the capacitive charge. By linear extrapolation, $Q_{c}=31.29 \mu \mathrm{C}$. Using this value and the intercept of Figure $8 \mathrm{~b}\left(i^{\prime}{ }^{\prime}\right)$, $\mathrm{Q}_{\mathrm{ads}}$ was found to be $53.11 \mu \mathrm{C}$. The amount of adsorbed QCT $(\Gamma)$ at the electrode surface is given by equation 3 .

$$
\Gamma=\frac{\mathrm{Q}_{\mathrm{ads}}}{\mathrm{nFA}}
$$

where $\mathrm{n}, \mathrm{F}, \mathrm{A}$ and $\mathrm{Q}_{\mathrm{ads}}$ are defined as in equation 2. Using equation 3 and the value of $\mathrm{Q}_{\mathrm{ads}}, \Gamma$ was found to be $6.95 \times 10^{-11} \mathrm{~mol} / \mathrm{cm}^{2}$, corresponding to monolayer adsorption of QCT at the electrode surface (Inzelt, 2010). This corresponds to about $4.18 \times 10^{13} \mathrm{QCT}$ molecules $/ \mathrm{cm}^{2}$.

\subsection{Determination of Reaction Order}

The anodic current densities, $\mathrm{j}_{\mathrm{a}}$, arising from the oxidation of QCT are the reaction rates multiplied by the charge transferred per mole of reaction (Faraday's constant) as shown in equation 4 (Atkins \& de Paula, 2006).

$$
\mathrm{j}_{\mathrm{a}}=\mathrm{Fk}_{\mathrm{a}}[\mathrm{QCT}]^{\mathrm{x}}
$$

where $\mathrm{x}$ is the reaction order, $\mathrm{k}_{\mathrm{a}}$ is the rate constant and $\mathrm{F}$ is the Faraday constant. Equation 4 can otherwise be written as:

$$
\log \mathrm{j}_{\mathrm{a}}=\log \mathrm{F}_{\mathrm{a}}+\mathrm{x} \log [\mathrm{QCT}]
$$

Figure 9 shows the plot of the logarithm of oxidation peak current densities against the logarithm of QCT concentrations. The slope of the straight line obtained gives the reaction order (Cheng \& Scott, 2006). This plot follows the equation $\log \mathrm{j}_{\mathrm{a}}=1.0326 \log \mathrm{C}_{\mathrm{QCT}}-0.7937(\mathrm{R}=0.999)$. The electrooxidation of $\mathrm{QCT}$ in $\mathrm{PB} \mathrm{pH} 3$ at CPE-EPB (10\%) therefore follows a first order kinetic with respect to QCT. 


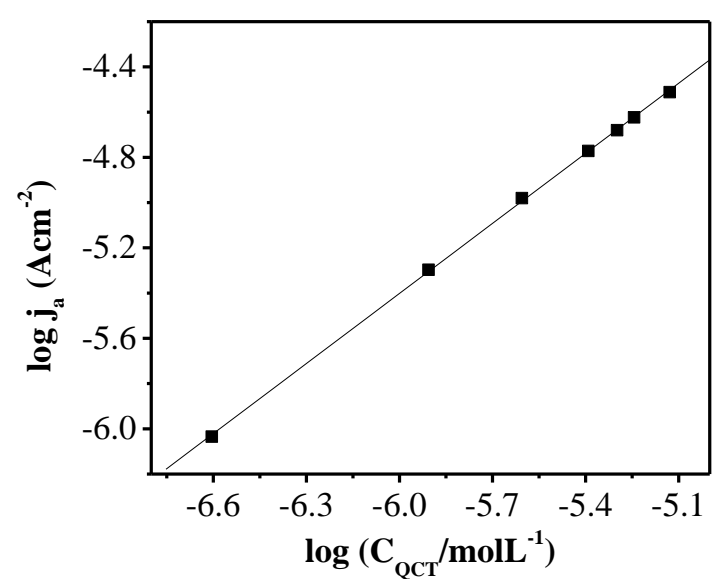

Figure 9. Relationship between the current density and concentration of QCT

\subsection{Interference of Some Organic Molecules}

The influence of some organic molecules, likely to coexist with QCT in real biological fluids, on the current response of QCT was investigated. The six interferents selected were uric acid (UA), ascorbic acid (AA), dopamine (DA), L-aspartic acid (AsA), citric acid (CA) and D-(+)-glucose. The results obtained are shown in Table 1. Varying interference levels were noted for the same interferent concentration.

Table 1. Effect of some interfering organic species on the signal of $20.7 \mu \mathrm{M}$ QCT.

\begin{tabular}{lll}
\hline Interfering organic species & Concentration $(\mu \mathrm{M})$ & Increase in peak current of QCT \\
\hline Ascorbic acid & 21.0 & $\approx 6 \%$ \\
Uric acid & 21.0 & $\approx 9 \%$ \\
Dopamine & 21.0 & $\approx 13 \%$ \\
L-Aspartic acid & 21.0 & $\approx-4 \%$ \\
Citric acid & 21.0 & $\approx-4 \%$ \\
D-(+)-Glucose & 21.0 & $\approx 6 \%$ \\
\hline
\end{tabular}

The most significant interferences were recorded with DA and UA while AsA and CA interfered least with the electrochemical signal of QCT. The increase in peak current could be explained by the superposition of signals as the oxidation potentials of QCT and DA, UA, AA or D-(+)-glucose are close to each other. On the other hand, As A and CA interfere with the preconcentration of QCT and this accounts for the peak current drop observed.

\subsection{Real Sample Analysis}

For practical analysis, the developed analytical method was applied to the quantification of QCT in human urine. The urine samples were diluted 100, 200 and 300 times with the PB supporting electrolyte solution as indicated in Table 2 to reduce interferences. QCT recoveries with concentrations $4.06 \mu \mathrm{M}$ and $6.10 \mu \mathrm{M}$ were then obtained. The results show that upon appropriate dilution, the proposed sensor can be an effective tool for the electrochemical probing of QCT in human urine samples.

Table 2. Quantification of QCT in human urine samples

\begin{tabular}{lllll}
\hline Sample & Urine dilution & QCT added $(\mu \mathrm{M})$ & Found $(\mu \mathrm{M})$ & Mean recovery $(\%)$ \\
\hline 1 & $\mathrm{x} 100$ & 4.06 & 3.65 & 89.9 \\
2 & $\mathrm{x} 200$ & 4.06 & 3.89 & 95.8 \\
3 & $\mathrm{x} 300$ & 4.06 & 3.93 & 96.8 \\
4 & $\mathrm{x} 300$ & 6.10 & 6.38 & 104.6 \\
\hline
\end{tabular}

\section{Conclusion}

A rapid, simple and inexpensive electroanalytical method has been developed for the determination of quercetin, based on an ionic liquid modified carbon paste electrode. Increased electrochemical effective electrode surface area as well as electrostatic interactions between the 1-ethylpyridinium moiety and quercetin favoured the preconcentration of the latter at the modified electrode surface. The interference studies showed a potential application of the elaborated sensor in the electroanalysis of quercetin in a biological fluid.

\section{Acknowledgments}

Financial support from the Academy of Science for the Developing World (Grant n॰12-117 RG/CHE/AF/AC-G 
awarded to Ignas K. Tonle and grant n॰ 07-052-LDC/CHE/AF/AC awarded to E. Ngameni) is gratefully acknowledged.

\section{References}

Atkins, P., \& de Paula, J. (2006). Atkins' Physical Chemistry, $8^{\text {th }}$ edition, W.H Freeman and Company, New York, 935.

Bogel-Lukasik, R., Goncalves, L. M. N., \& Bogel-Lukasik, E. (2010a). Phase equilibrium phenomena in solutions involving tannins, flavonoids and ionic liquids. Green Chem., 12, 1947-1953. http://dx.doi.org/10.1039/c0gc00308e

Bogel-Lukasik, R., Matkowska, D., Bogel-Lukasik, E., \& Hofman, T. (2010c). Selectivity enhancement in the catalytic heterogeneous hydrogenation of limonene in supercritical carbon dioxide by an ionic liquid. Fluid Phase Equilib., 293, 168-174. http://dx.doi.org/10.1016/j.supflu.2010.04.011

Bogel-Lukasik, R., Matkowska, D., Zakrzewska, M. E., Bogel-Lukasik, E., \& Hofman, T. (2010b). The phase envelopes of alternative solvents (ionic liquid, $\mathrm{CO} 2$ ) and building blocks of biomass origin (lactic acid, propionic acid). Fluid Phase Equilib., 295, 177-185. http://dx.doi.org/10.1016/j.fluid.2010.05.013

Brett, A. M. O., \& Ghica M. E. (2003). Electrochemical oxidation of quercetin. Electroanalysis, 15, 1745-1750. http://dx.doi.org/10.1002/elan.200302800

Burns, J., Gardner, P. T., \& O'Neil, J. (2000). Relationship among antioxidant activity, vasidilation capacity and phenolic content of red wines. J. Agric. Food Chem., 48, 220-230. http://dx.doi.org/10.1021/jf9909757

Cao, Y., Zhang, X., Fang, Y., \& Ye, J. (2001). Determination of active ingredients of Apocynum venetum by capillary electrophoresis with electrochemical detection. Mikrochim. Acta, 137, 57-62. http://dx.doi.org/10.1007/s006040170028

Cheng, H., \& Scott, K. (2006). Determination of kinetic parameters for borohydride oxidation on a rotating $\mathrm{Au}$ disk electrode. Electrochim. Acta, 51, 3429-3433. http://dx.doi.org/10.1016/j.electacta.2005.09.038

Cook, N. C., \& Samman, S. (1996). Flavonoids-chemistry, metabolism, cardioprotective effects, and dietary sources. J. Nutr. Biochem., 7, 66-76. http://dx.doi.org/10.1016/0955-2863(95)00168-9

Dall'Agnol, R., Ferraz, A., Bernardi, A. P., Albring, D., Nor, C., Sarmento, L., Lamb, L., Hass, M., von Poser, G., \& Schapoval, E. E. S. (2003). Antimicrobial activity of some Hypericum species. Phytomedicine, 10, 511-516. http://dx.doi.org/10.1078/094471103322331476

Domanska, U., \& Bogel-Lukasik, R. (2005). Solubility of ethyl-(2-hydroxyethyl)-dimethyl-ammonium bromide in alcohols (C2-C12). Fluid Phase Equilib., 233, 220-227. http://dx.doi.org/10.1016/j.fluid.2005.05.015

Franzoi, A. C., Vieira, I. C., Scheeren, C. W., \& Dupont, J. (2010). Development of quercetin biosensor through Immobilizing Laccase in a modified beta-Cyclodextrin matrix containing Ag nanoparticles in ionic liquid. Electroanalysis, 12, 1376-1385. http://dx.doi.org/10.1002/elan.200900591

Gonzalez-Segovia, R., Quintanar, J. L., Salinas, E., Ceballos-Salazar, R., Aviles-Jimenez, F., \& Torres-Lopez, J. (2008). Effect of the flavonoid quercetin on inflammation and lipid peroxidation induced by Helicobacter pylori in gastric mucosa of guinea pig. J. Gastroenterol., 43, 441-447. http://dx.doi.org/10.1007/s00535-008-2184-7

Havsteen, B. (1983). Flavonoids, a class of natural products of high pharmacological potency. Biochem. Pharmacol., 32, 1141-1148. http://dx.doi.org/10.1016/0006-2952(83)90262-9

He, J. B., Wang, Y., Deng, N., \& Lin, X. Q. (2007). Study of the adsorption and oxidation of antioxidant rutin by $\begin{array}{llll}\text { cyclic voltammetry-voltabsorptometry. } & \text { Bioelectrochem., } & 71, & 157-163 .\end{array}$ http://dx.doi.org/10.1016/j.bioelechem.2007.03.003

Hollman, P. C. H., Gaag, M. V. D., Mengelers, M. J. B., Van Trijp, J. M. P., DeVries, J. H. M., \& Katan, M. B. (1996). The sugar moiety is a major determinant of the absorption of dietary flavonoid glycosides in man. Free Radical Biol. Med., 21, 703-707. http://dx.doi.org/10.1016/0891-5849(96)00129-3

Inzelt, G. (2010) In Electroanalytical methods: Guide to experiments and applications, $2^{\text {nd }}$ edition (Ed. F. Scholz), Springer-Verlag, Berlin, pp. 147-158. http://dx.doi.org/10.1007/978-3-642-02915-8_7

Izzo, A. A., Carlo, G. D., Mascolo, N., Capasso, F., \& Autore, G. (1994). Effect of quercetin on gastrointestinal tract. Phytother. Res., 8, 179-185. http://dx.doi.org/10.1002/ptr.2650080313

Jiuji, G., Wei, K., Le, W., Haixia, R., Baoxian, Y., \& Qi, S. (2013). Simultaneous determination of rutin and 
quercetin at a graphite oxide and ionic liquid modified electrode by square wave voltammetry. Sens. Lett., 11, 603-606. http://dx.doi.org/10.1166/sl.2013.2823

Jones, D. J. L., Lim, C. K., Ferry, D. R., \& Gescher, A. (1998). Determination of quercetin in human plasma by HPLC with spectrophotometric or electrochemical detection. Biomed. Chromatogr., 12, $232-235$. http://dx.doi.org/10.1002/(SICI)1099-0801(199807/08)12:4<232::AID-BMC740>3.0.CO;2-1

Laviron, E. (1974). Adsorption, autoinhibition and autocatalysis in polarography and in linear potential sweep voltammetry. Electroanal. Chem. Interf. Electrochem., 52, 355-393.

http://dx.doi.org/10.1016/ S0022-0728(74)80448-1

Lin, X. Q., He, J. B., \& Zha, Z. G. (2006). Simultaneous determination of quercetin and rutin at a multi-wall carbon-nanotube paste electrode by reversing differential pulse voltammetry. Sens. Actuators B, 119, 608614. http://dx.doi.org/10.1016/j.snb.2006.01.016

Liu, X., Wang, Y., Kong, J., Nie, C., \& Lin, X. (2012). Application of ionic liquids in the microwave-assisted extraction of quercetin from Chinese herbal medicine. Anal. Methods, 4, 1012-1018. http://dx.doi.org/10.1039/c2ay05834k

Maleki, N., Safavi, A., \& Tajabadi, F. (2006). High-performance carbon composite electrode based on an ionic liquid as a binder. Anal. Chem., 2006, 78, 3820-3826. http://dx.doi.org/10.1021/ac060070+

Maleki, N., Safavi, A., Sedaghati, F., \& Tajabadi, F. (2007). Efficient electrocatalysis of L-cysteine oxidation at carbon ionic liquid electrode. Anal. Biochem., 369, 149-149. http://dx.doi.org/10.1016/j.ab.2007.04.024

Opallo, M. \& Lesniewski, A. (2011). A review on electrodes modified with ionic liquids. J. Electroanal. Chem., 656, 2-16. http://dx.doi.org/10.1016/j.jelechem.2011.01.008

Osman, H. E., Maalej, N., Shanmuganayagam, D., \& Folts, J. D. (1998). Grape juice but not orange or grape fruit juice inhibits plate activity in dogs and monkey's. J. Nutr., 128, 2307-2312.

Pejic, N., Kuntic, V., Vujic, Z., \& Micic, S. (2004). Direct spectrophotometric determination of quercetin in the presence of ascorbic acid. Il Farmaco, 59, 21-24. http://dx.doi.org/10.1016/j.farmac.2003.07.013

Piovesan, J. V., \& Spinelli, A. (2014). Determination of quercetin in a pharmaceutical sample by square-wave voltammetry using a poly(vinylpyrrolidone)-modified carbon-paste electrode. J. Braz. Chem. Soc., 25, 517-525. http://dx.doi.org/10.5935/0103-5053.20140019

Qu, L.-N., Wu, J., Sun, X.-Y., Xi, M.-Y., \& Sun, W. (2010). Application of multi-walled carbon nanotube modified carbon ionic liquid electrode for the voltammetric detection of dopamine. J. Chin. Chem. Soc., 57, 701-707.http://dx.doi.org/10.1002/jccs.201000098

Ranjbari, E., Biparva, P., \& Hadjmohammadi, M. R. (2012). Utilization of inverted dispersive liquid-liquid microextraction followed by HPLC-UV as a sensitive and efficient method for the extraction and determination of quercetin in honey and biological samples. Talanta, 89, 117-123. http://dx.doi.org/10.1016/j.talanta.2011.11.079

Rauha, J. P., Remes, S., Heinonen, M., Hopia, A., Kahkonen, M., Kujala, T., Pihlaja, K., Vuorela, H., \& Vuorela, P. (2000). Antimicrobial effects of Finnish plant extracts containing flavonoids and other phenolic compounds. Int. J. .Food Microbiol., 56, 3-12. http://dx.doi.org/10.1016/S0168-1605(00)00218-X

Ren, W., Qiao, Z., Wang, H., Zhu, L., \& Zhang, L. (2003). Flavonoids: Promising anticancer agents. Med. Res. Rev., 23, 519-534. http://dx.doi.org/10.1002/med.10033

Safavi, A., Maleki, N., Moradlou, O., \& Sorouni, M. (2008). Direct electrochemistry of hemoglobin and its electrocatalytic effect based on its direct immobilization on carbon ionic liquid electrode. Electrochem. Comm., 10, 420-423. http://dx.doi.org/10.1016/j.elecom.2007.12.026

Sharififar, F., Dehghn-Nudeh, G., \& Mirtajaldini, M. (2009). Major flavonoids with antioxidant activity from Teucrium polium. Food Chem., 112, 885-888. http://dx.doi.org/10.1016/j.foodchem.2008.06.064

Tcheumi, H. L., Tonle, I. K., Ngameni, E., \& Walcarius, A. (2010). Electrochemical analysis of methylparathion pesticide by a gemini surfactant-intercalated clay-modified electrode. Talanta, 81, 972-979. http://dx.doi.org/10.1016/j.talanta.2010.01.049

Tchieno, F. M. M., Njanja, E., Tapondjou, L. A., \& Tonle, I. K. (2014). Adsorptive stripping voltammetric determination of mangiferin using an activated chitosan modified carbon paste electrode. Am. J. Anal. Chem., 5, 424-432. http://dx.doi.org/10.4236/ajac.2014.57051 
Teresita, G., Ester, R. A., Osvaldo, J. A., \& Eugenia. P. L. (2001). Anti-inflammatory properties of plant flavonoids. Effects of rutin, quercetin and hesperidin on adjuvant arthritis in rat. Il Farmaco., 56, 683-687. http://dx.doi.org/10.1016/S0014-827X(01)01111-9

Undeger, U., Aydin, S., Basaran, A. A., \& Basaran, N. (2004). The modulating effects of quercetin and rutin on the mitomycin C induced DNA damage. Toxicol. Lett., 151, 143-149. http://dx.doi.org/10.1016/j.toxlet.2003.12.071

Vessal, M., Hemmati, M., \& Vasei, M. (2003). Antidiabetic effects of quercetin in streptozocin induced diabetic rats. Comp. Biochem. Physiol. C-Pharmacol. Toxicol. Endocrinol., 135, 357-364. http://dx.doi.org/10.1016/S1532-0456(03)00140-6

Wang, Q., Ding, F., Li, H., He, P., \& Fang, Y. (2003). Determination of hydrochlorothiazide and rutin in Chinese herb medicines and human urine by capillary zone electrophoresis with amperometric detection. J. Pharm. Biomed. Anal., 30, 1507-1514. http://dx.doi.org/10.1016/S0731-7085(02)00540-X

Xiao, D., Yuan, D., He, H., \& Gao, M. (2013). Microwave assisted one-step green synthesis of fluorescent carbon nanoparticles from ionic liquids and their application as novel fluorescence probe for quercetin determination. J. Lumin., 140, 120-125. http://dx.doi.org/10.1016/j.jlumin.2013.02.032

Xiao, P., Zhao, F., \& Zeng, B. (2007). Voltammetric determination of quercetin at a multi-walled carbon nanotubes paste electrode. Microchem. J., 85, 244-249. http://dx.doi.org/10.1016/j.microc.2006.06.004

Xu, W., Chu, K., Li, H., Zhang, Y., Zheng, H., Chen, R., \& Chen, L. (2012). Ionic liquid-based microwave-assisted extraction of flavonoids from Bauhinia championii (Benth.) Benth. Molecules, 17, 14323-14335. http://dx.doi.org/10.3390/molecules171214323

Yin, H., Zhou, Y., Xu, J., Ai, S., Cui, L., \& Zhu, L. (2010). Amperometric biosensor based on tyrosinase immobilized onto multiwalled carbon nanotubes-cobalt phthalocyanine-silk fibroin film and its application to determine bisphenol A. Anal. Chim. Acta, 659, 144-150. http://dx.doi.org/10.1016/j.aca.2009.11.051

Yola, M. L., \& Atar, N. (2014). A novel voltammetric sensor based on gold nanoparticles involved in p-aminothiophenol functionalized multi-walled carbon nanotubes: Application to the simultaneous determination of quercetin and rutin. Electrochim. Acta, 119, 24-31. http://dx.doi.org/10.1016/j.electacta.2013.12.028

Zheng, Y., Ye, L., Yan, L., \& Gao Y. (2014). The electrochemical behavior and determination of quercetin in choline chloride/urea deep eutectic solvent electrolyte based on abrasively immobilized multi-wall carbon nanotubes modified electrode. Int. J. Electrochem. Sci., 9, 238-248.

Zhou, A. \& Sadik, O. A. (2008). Comparative analysis of quercetin oxidation by electrochemical, enzymatic, autoxidation, and free radical generation techniques: A mechanistic study. J. Agric. Food Chem., 56, 12081-12091. http://dx.doi.org/10.1021/jf802413v

Zhu, T., Wentao, B., \& Kyungho, R. (2011). Extraction and determination of quercetin and myricetin from Chamaecyparis obtusa by ionic liquids-based Monolithic cartridge. Chin. J. Chem., 29, 1759-1763. http://dx.doi.org/10.1002/cjoc.201180280

\section{Copyrights}

Copyright for this article is retained by the author(s), with first publication rights granted to the journal.

This is an open-access article distributed under the terms and conditions of the Creative Commons Attribution license (http://creativecommons.org/licenses/by/3.0/). 